\title{
Clay Minerals and the Ancient Martian Carbon Cycle
}

\author{
T.F.BRISTOW ${ }^{1}$, E. B. RAMPE ${ }^{2}$, D.T. VANIMAN ${ }^{3}$, D. F. \\ BLAKE $^{1}$, B. SUTTER ${ }^{2}$, J. P. GROTZINGER ${ }^{4}$ \\ ${ }^{1}$ NASA Ames Research Center, Moffett Field, CA USA \\ (thomas.f.bristow@nasa.gov) \\ ${ }^{2}$ NASA Johnson Space Center, Houston, TX USA \\ ${ }^{3}$ Planetary Science Institute, Tuscon, AZ USA \\ ${ }^{4}$ California Inst. Of Technology, Pasadena, CA USA
}

Clay minerals play an important role in the global carbon cycle on Earth. Their formation in weathering profiles and during authigenesis in oceanic sediments are part of mechanisms that regulate atmospheric $\mathrm{CO}_{2}$ levels and oceanic carbonate chemistry. Intimate associations between clay minerals and organic material also have a reciprocal influence on the preservation and transformation of both these components as they enter the rock record.

Clay minerals are widely detected in Noachian and Early Hesperian martian terrains from orbit, but their origins remain debated and the extent of their role in the ancient martian carbon cycle is unclear. Here we report ongoing investigations of the nature and origin of clay minerals in 3.5 Ga lake sediments documented by Mars Science Laboratory at Gale crater. Smectitic clay minerals are pervasive in lake mudstone samples that span $>400 \mathrm{~m}$ of stratigraphy and comprise up to $\sim 30$ wt. $\%$ of the rock. A detrital origin was proposed for these clay minerals prior to landing. However, observed relationships between $\mathrm{Mg}$-rich trioctahedral and Al-rich dioctahedral smectites and sedimentological, mineralogical, and geochemical indicators of changing lacustrine conditions support formation close to the time of deposition. Smectites are a particularly reactive group of clay minerals with respect to organic molecules. Thus, evidence of smectite formation in aqueous near-surface martian environments indicates potential involvement in the sequestratration of organic carbon, and an influence on the inorganic carbon chemistry of the Gale lake system.

Gale smectite shows little evidence of burial diagnetic transformations (chloritziation, illitization) typically observed in terrestrial sedimentary basins. Such transformations accompany the maturation of sedimentary organic matter, enhancing catagenesis and migration of hydrocarbons. However, localized diagenesis appears to have canabalized clay minerals in certain areas. Given the global predominace of smectite clay minerals on Mars and lack of plate tectonics, this style of clay mineral diagenesis may be the primary pathway closing the loop of the ancient martian carbon cycle. 